\title{
A Simplified Micromechanical Model of Compressive Strength of Fiber-Reinforced Cementitious Composites
}

\author{
Victor C. $\mathrm{Li}$
}

Advanced Civil Engineering Materials Research Laboratory, Department of Civil Engineering, University of Michigan, MI 48109-2125, USA

\begin{abstract}
A micromechanical model is constructed for the compressive strength of fiber-reinforced cementitious composites (FRCs). This model is based on the classical models of compressive failure of brittle solids in which sliding microcracks induce wing-crack growth under compression loads. The concept of increased microcrack sliding resistance and wing-crack growth retardation associated with fiber bridging is exploited to produce a strengthening effect of fibers in composite strength. The concept of defect introduction associated with fiber volume fraction is included to produce a composite strength degradation. The combined effect results in composite compressive strength which increases initially and subsequently drops with increasing fiber content, as has been observed in FRCs reinforced with a variety of fibers.
\end{abstract}

Keywords: Fiber-reinforced cementitious composites, concrete, compressive strength, fiber bridging, micromechanics, model.

\section{INTRODUCTION}

The addition of fiber to achieve improved tensile properties in brittle matrixes has received a great deal of attention in fibrous composite science and engineering in recent years. In cementitious composites, models have been constructed to study various tensile properties, including pseudo strain-hardening properties (e.g. Refs 1,2) and fracture properties. ${ }^{3-5}$ The influence of fibers on compressive strength, however, has not received as much attention. It is interesting to note that both increase and decrease of compressive strength with different fiber types have been experimentally observed. Even for the same material, there is mounting evidence that compressive strength may first rise, then drop, with increasing fiber volume fraction. These observations suggest that the addition of fibers in a cement composite leads to a competing process of strength improvement as well as degradation.

Strength improvement is a likely manifestation of increased resistance to microcrack sliding and extension, whereas strength degradation is a likely manifestation of increase in either pore or microcrack density, as a result of fiber addition. The pores may be related to insuffucient compaction and the additional microcracks may be related to touching fibers, (unbonded) fiber end cracks, poor fiber/matrix bonding, or poor adhesion between filaments within fiber bundles. Clearly, these defects are sensitive to fiber type, cement matrix type and the composite fabrication details (mixing, casting and curing processes, and chemical additive, age, etc.) It should be noted that much of the strengthening and degradation effects of fibers outlined above are of a speculative nature. Jakobsen, ${ }^{6}$ however, did observe via thin-section microscopy that the hydrated cement paste adhering to polypropylene fibers has coarser microstructure with higher capillary porosity. Such weak zones introduced by fibers may act as the defects or damage from which macroscopic cracks may initiate under compressive loading. Micromechanical experiments are needed to establish the basic strengthening and weakening micromechanics of fibers. In this paper, we present a preliminary micromechanical model which captures the salient features of some of these concepts and relates them to experimentally observed compressive strength variations in fiberreinforced cementitious composites (FRCs).

Cement \& Concrete Composites 0958-9465/92/\$5.00 \& 1992 Elsevier Science Publishers Ltd, England. Printed in Great Britain 
The present model is fundamentally based on well-known micromechanical models of compressive failure in brittle solids. ${ }^{7-10}$ The influence of fibers on microcrack sliding and extension is based on crack bridging studies carried out in recent years. The model is kept as simple as possible in order to obtain closed-form solutions which elucidate the micromechanical parameters controlling the strengthening and the weakening mechanisms. It is found that, depending on the effectiveness and amount of fiber bridging, and the degree to which fibers introduce defects to the composite, both increase and decrease of compressive strength can be derived from increasing fiber content. Furthermore, it is identified that the fiber/matrix bond strength and a snubbing coefficient can lead to higher compressive strength for a given fiber type and aspect ratio and for a given composite fabrication process. There is a strong need to comprehend better how defects are generated for various fiber types, and how they can be reduced by various fabrication processes.

This paper aims at providing a basic framework which relates microstructures and micromechanisms to composite compressive strength. Detail aspects of this framework should be refined as our understanding of the fundamental micromechanisms of compressive failure is improved. Although fibers are used mainly in improving tensile properties, research results from the present study may be used for fiber type and content selection to minimize compressive strength degradation. While compressive strength gain is likely to be moderate under uniaxial compression loading, Yin et al. ${ }^{14,15}$ suggested that much higher compressive strength gain is possible under biaxial loading conditions. For example, a 35\% increase in biaxial strength is achieved with $2 \%$ of steel fibers, which typically gives only a uniaxial compressive strength increase of a few per cent. This 'passive confinement' effect of fibers is the subject of a micromechanical study in a present research effort at the University of Michigan, building on the framework presented in this paper.

\section{EXPERIMENTAL OBSERVATIONS}

Figure 1 shows compressive strengths of cementitious composites reinforced with various fiber types. The data have been normalized by the matrix compressive strength, i.e. at fiber volume fraction $V_{\mathrm{f}}=0$. Table 1 contains information on the details of the fiber and matrix. It can be seen that there is no simple correlation between compressive strength and fiber content. For example, rapid strengthening up to more than twice the matrix compressive strength was achieved for the HM-50 FRC with high water/cement $(w / c)$ ratio. In contrast, degradation was extensive in the Kevlar FRC. The other composites with various fiber types (steel. Dolanit, Krenit, and carbon) generally show an initial compressive strength rise, followed by decay, dropping in the case of Krenit (at 28 days) by as much as a factor of 2 at $V_{\mathrm{f}}=2 \%$. Peak compressive strength is reached typically at $V_{f}=0.5-1 \%$. The exception is the Dramix FRC. In the Dramix FRC, specially gapgraded cement with high microsilica content was used for the matrix, which was processed with high-frequency vibration. Continued compressive strength improvement was observed up to $V_{\mathrm{f}}=12 \%$. It should be clear that compressive strength variation with fiber content is not only a function of fiber type, but is dependent on other factors such as age (as reflected in the 7- and 28days Krenit FRC data), w/c ratio (as reflected in the HM-50 FRC), particle grading, chemical admixtures and the composite fabrication process (as reflected in the Dramix FRC). However, within each data set used in Fig. 1, these parameters are fixed.

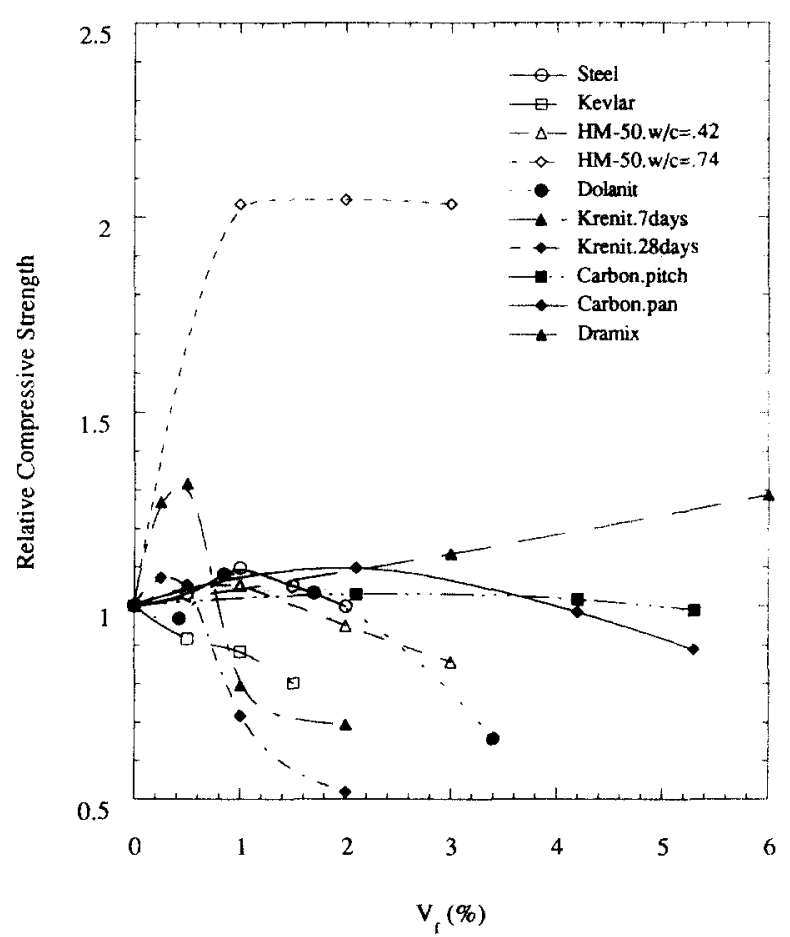

Fig. 1. Compressive strength of various fiber-reinforced cementitious composites relative to the matrix compressive strength, as a function of fiber volume fraction. 
Table 1. Fiber and matrix characteristics of the FRCs tested in uniaxial compression (Fig. 1)

\begin{tabular}{|c|c|c|c|c|c|c|c|}
\hline \multirow[b]{2}{*}{ Type } & \multicolumn{2}{|l|}{ Fiber } & \multicolumn{5}{|c|}{ Matrix } \\
\hline & Generic name & $\underset{(m m)}{L_{f}}$ & $\begin{array}{c}d_{\mathrm{f}} \\
(\mu \mathrm{m})\end{array}$ & Type & $w / c$ & $\begin{array}{c}\text { Age } \\
\text { (days) }\end{array}$ & Reference \\
\hline $\mathrm{HM}-50$ & Aramid & 6 & $12 \cdot 4$ & $\begin{array}{l}\text { Cement paste } \\
\text { with microsilica }\end{array}$ & $\begin{array}{l}0.42 \\
0.74\end{array}$ & 14 & 34 \\
\hline Kevlar & Aramid & $6 \cdot 4$ & 12 & Mortar & $0 \cdot 40$ & 14 & 35 \\
\hline Dolanit & Polyacrylonitrile & 6 & 104 & Concrete & $0 \cdot 45$ & NA & 36 \\
\hline Krenit & Polypropylene & 12 & $\begin{array}{l}\text { Cut from } \\
\text { thin foil }\end{array}$ & $\begin{array}{l}\text { Concrete with } \\
\text { fly ash and } \\
\text { microsilica }\end{array}$ & 0.50 & $\begin{array}{r}7 \\
28\end{array}$ & 6 \\
\hline Carbon & Pitch type & 3 & $14 \cdot 5$ & $\begin{array}{l}\text { Cement paste } \\
\text { with microsilica }\end{array}$ & 0.47 & 7 & 37 \\
\hline Carbon & Pan type & 3 & 7 & $\begin{array}{l}\text { Cement paste } \\
\text { with microsilica }\end{array}$ & 0.47 & 7 & 37 \\
\hline Steel & Steel & 25 & 250 & Mortar & $0 \cdot 40$ & 14 & 35 \\
\hline Dramix & Brass-coated steel & 6 & 150 & Mortar & 0.20 & 4 & 38 \\
\hline
\end{tabular}

\section{A MICROMECHANICAL MODEL}

\section{Brief review of crack stability and strength concepts}

In a brittle solid, tensile failure is generally attributed to the unstable extension of a critical tensile crack (e.g. Ref. 16). The stress intensity factor $K_{\mathrm{I}}$ for such a crack takes the general form of

$$
K_{\mathrm{I}}=\alpha Q \sigma \sqrt{\pi a}
$$

where $Q$ is a dimensionless geometric correction factor close to unity. It is seen that the crack driving force $K_{\mathrm{I}}$ increases with the crack length $a$, so that once $K_{1}$ reaches $K_{\mathrm{IC}}$ with increasing load $\sigma$, the crack will be self-driven. Therefore, tensile cracks are inherently unstable. We consider that the load which leads to this instability is the tensile strength of the solid. Although the presence of other microcracks in the body can raise the stress intensity factor, as represented by the interaction factor $\alpha>1$, this crack-crack interaction is not necessary for the instability of the crack system.

We now consider a microcrack length of $2 \alpha$ orientated at an angle $\beta$ (Fig. 2) in a brittle solid subjected to a uniaxial compressive load $\sigma$. The compressive load generates a shear stress $\tau$ which causes frictional sliding on the crack faces. The shear sliding in turn creates a singular stress field with tensile components on opposite quadrants, causing the initiation of tensile 'wing-cracks'. A simplified approximate expression for the stress intensity factor of straight wing-cracks of length $l$ parallel to the loading axis for the most critical sliding crack with orientation $\beta=45^{\circ}$ has been
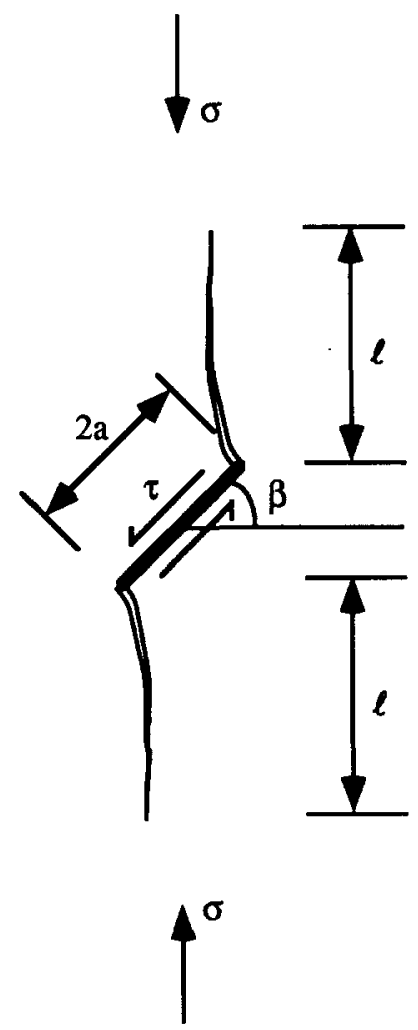

Fig. 2. Wing-crack growth induced by sliding of microcrack as the basic mechanism of compressive failure in brittle solids.

obtained by Horii \& Nemat-Nasser, ${ }^{3}$ and is given by:

$$
K_{\mathrm{I}}=\frac{2 \tau \sqrt{\pi a}}{\pi \sqrt{2(l / a+0 \cdot 27)}}
$$

where

$$
\tau=\frac{1}{2} \sigma(1-\mu)
$$


and $\mu$ is a coefficient of friction against shear sliding of the crack faces. Figure 3 shows the stress intensity factor variation with wing-crack length using eqn (2). The normalized crack driving force $K_{\mathrm{I}} / \sigma \sqrt{ }(\pi a)$ drops rapidly as the wing-crack length (l/a) extends. This means that a wing-crack is inherently stable, requiring increasing load to continue its growth. Clearly, brittle solids do not have infinite compressive strength. What causes these wing-cracks to lose their stability is crack-crack interaction. In general, crack interaction raises the stress intensity factor and is a function of the crack density (i.e. how close the interacting cracks are to each other). Crack interaction, therefore, is critical in leading to a critical load in compression - the compressive strength of the solid with many microcracks.

In many brittle solids, and specifically cementitious materials, microdefects are probably in the form of both microcracks and air voids. Sammis \& Ashby ${ }^{17}$ showed that stress concentration at these voids under compressive stress can lead to microcrack growth in the direction of the applied load. Again, although initially unstable, these void-induced microcracks are stable as their lengths increase. Indeed, Kemeny \& Cook $^{10}$ pointed out that the stress intensity factors in both wing-cracks and void-induced microcracks have very similar forms. This is illustrated in Fig. 3, which also shows the crack driving force for a microcrack emanating from a void of radius $R$. Hence crack-crack interaction is necessary to lead to compression failure in brittle solids with void defects as well.

Our interest in compressive strength in the present work implies our intended focus on the

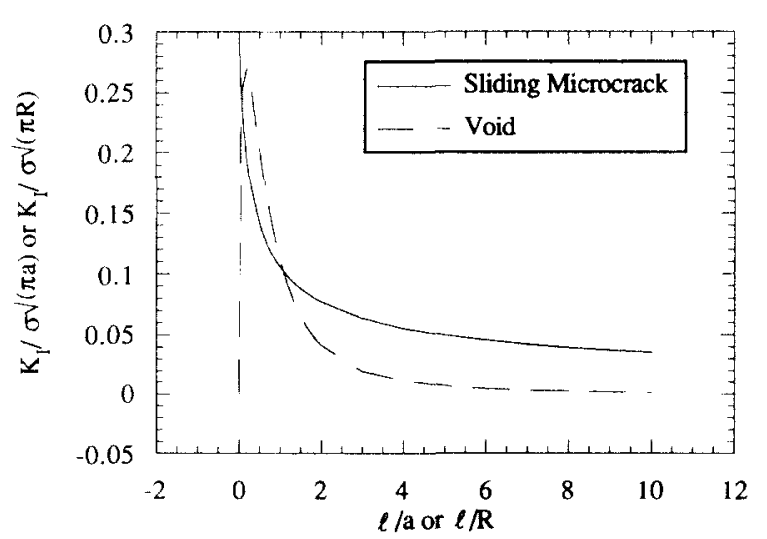

Fig. 3. Rapid decay of normalized stress intensity factor with growth of tensile microcrack of length $l$ from sliding microcrack of length $2 a$ or void of radius $R$. The growth of tensile microcracks is aligned with the major compression axis. stage when the wing-cracks have grown to the extent that interactions begin to take effect. The initial differences between sliding microcracks and air voids are therefore ignored, and the subsequent formulations are based solely on the expressions which govern wing-crack growth induced by sliding microcracks.

\section{Crack interactions}

The details of crack interactions in tensile loading, and particularly in compressive loading are at present not well understood. Under overall tensile loading, Huang \& $\mathrm{Li}^{18}$ studied interactions between cement-aggregate interfacial cracks following a Fuller size distribution to obtain the $\alpha$-value in eqn (1). Horii ${ }^{19}$ assumed a uniform microcrack size distribution with spatially collinear arrangements in order to derive the tension softening curve of concrete. Similar assumptions are made by Bazant ${ }^{20}$ and Ortiz ${ }^{21}$ in their analyses of microcrack coalescence and its implications to macroscopic tensile load instability.

Under overall compressive stress fields, Ashby \& Hallam ${ }^{9}$ assumed crack interactions to be in the form of beam buckling. The beams are assumed to have been formed by subparallel growing wingcracks. A greatly idealized model, proposed by Kemeny \& Cook, ${ }^{11}$ treats the axial splitting failure phenomenon as a result of collinear crack interactions. This collinear crack interaction model will be adopted here for its simplicity in form, although the resulting compressive strength calculation should be regarded as a lower bound due to the stronger-than-expected interaction effect. Further simplification is afforded (as in Ref. 9) by considering that the final failure is dominated by sliding microcracks which are lying at the most critical angle, i.e. at $\beta=45^{\circ}$. For this model, following Rooke \& Cartwright, ${ }^{22}$ the stress intensity factor under uniaxial compression loading is given by:

$$
K_{\mathrm{I}}=\frac{\sqrt{2} a \tau}{\sqrt{b \sin (\pi l / b)}} \text { for } a<l<b
$$

The intensity of crack interaction is dictated by $l / b$, where $b$ defines the center-to-center distance between sliding microcracks; $l$ varies from its initial length $a$ to $b$, when the wing-cracks would have coalesced into a splitting fracture. The parameter $a / b$ may therefore be regarded as an initial damage parameter of the solid in this model. For example, a poorly compacted concrete may be expected to have a large $a / b$ value. 
Assuming that linear elastic fracture mechanics holds on the scale of microdefects and wingcracks, eqn (4) may be combined with the crack propagation condition

$$
K_{\mathrm{I}}=K_{\mathrm{m}}
$$

where $K_{\mathrm{m}}$ is the fracture toughness of the cementitious material without fibers, and inverted to calculate the compression load required to maintain the normalized crack length $(l / a)$ :

$$
\frac{\sigma \sqrt{\pi a}}{K_{\mathrm{m}}}=\frac{\sqrt{2 \pi \sin [\pi(l / a)(a / b)}]}{(1-\mu) \sqrt{(a / b)}}
$$

This solution is illustrated in Fig. 4 for four different initial damage levels $(a / b)$. The compressive strength is given by the peak of these curves, and is shown to decrease with the amount of initial damage. It is interesting to note that for tensile loading, $\sigma \sqrt{ }(\pi a) / K_{\mathrm{m}}$ is of the order of unity. Since, for cementitious materials, the compressive strength is typically one order of magnitude higher, Fig. 4 suggests that the typical damage level must be in the range of $0 \cdot 05-0 \cdot 2$. For the calculations to follow, we choose $a / b=0 \cdot 1$ as the natural flaw density of typical cementitious materials without fibers.

\section{STRENGTHENING EFFECT OF FIBER ADDITION}

The presence of fibers in a cementitious composite may introduce two types of strengthening effects. Improvement of compressive strength may come from greater resistance to sliding of

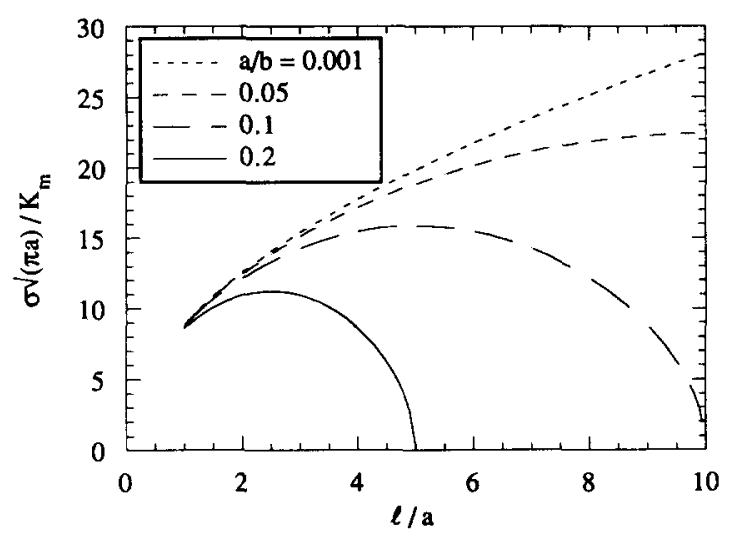

Fig. 4. Normalized compression load required to drive a wing-crack of length $l$, for four different initial damage levels $a / b$. Calculated for $\mu=0 \cdot 5$. pre-existing microcracks, so that the driving force for the wing-cracks would be diminished. A second positive influence of fibers is in the direct reduction of wing-crack growth rate due to wingcrack bridging, effectively producing a higher fracture toughness against which the wing-crack has to propagate. It is expected that the effect on sliding resistance dominates in the early stage when wing-cracks have not been formed, whereas both effects become important as wing-cracks grow and interactions between them subsume.

\section{Sliding resistance}

Figure 5 shows a sliding mode II type crack bridged by fibers. Sliding resistance of the crack is provided by crack face friction, as before, and by the additional force needed to debond and pull the fibers out. If the bridging force is controlled solely by the fiber/matrix interface bond properties, then the case of sliding resistance is identical to that of a closing pressure exerted by bridging fibers against a mode I type crack opening. In this case, the bridging stress as a function of crack face sliding (or opening) has been derived by $\mathrm{Li}^{13}$ in terms of the interface bond strength $\tau_{f}$, fiber aspect ratio $L_{\mathrm{f}} / d_{\mathrm{f}}$, and volume fraction $V_{\mathrm{f}}$, and taking into account the randomness of fiber distribution and orientation with respect to the sliding crack plane:

$$
\tau_{\mathrm{B}}(\tilde{\delta})=\frac{1}{2} \tau_{\mathrm{f}} V_{\mathrm{f}}\left(\frac{L_{\mathrm{f}}}{d_{\mathrm{f}}}\right)(1-\tilde{\delta})^{2} \text { for } 1>\tilde{\delta}>\tilde{\delta}^{*}
$$

In eqn (7) $\tilde{\delta}\left[\equiv \delta /\left(L_{\mathrm{f}} / 2\right)\right]$ is the relative slippage between the two faces of a sliding crack normalized by half the fiber length; $\tilde{\delta}^{*}$ is the normalized sliding magnitude at the maximum bridging stress, associated with the stage of fiber loading when debonding of the interface has been completed

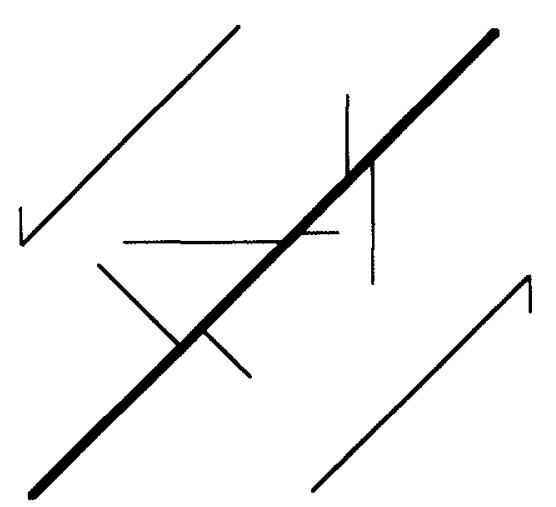

Fig. 5. Schematics showing the bridging actions of fibers crossing a sliding microcrack at various angles. 
and just prior to full fiber slippage. For all practical purposes, and particularly for our interest in modeling the compressive strength of the composite when $\tilde{\delta}>>\tilde{\delta}^{*}$, we may assume $\tilde{\delta}^{*}$ to be zero. This assumption is likely to be more accurate for the stage when the wing-cracks have grown to such an extent that their interaction leads to loss of stability, i.e. when compressive failure is approached.

Additional bridging forces may be introduced due to the inclined orientation of the fiber to the sliding crack plane. This angle effect causes fibers to bend as the cracks slide (or open in the case of a mode I crack). The additional bridging force associated with fiber bending has been analyzed by Morton \& Groves ${ }^{23}$ for fibers which show elastic-plastic behavior, as in the case of steel fibers, for fibers which show elastic-brittle behavior, as in the case of $\mathrm{SiC}$ fibers and potentially some carbon fibers, ${ }^{24}$ and for fibers which behave very flexibly, as in the case of most polymeric fibers. ${ }^{12}$ In the interest of mathematical tractability, we adopt the flexible fiber assumption in the present work. We note that these assumptions will need to be modified for more specific fiber types, and for the situation when the compressive bearing pressure of a bending fiber on the matrix at the bridge site may cause local spalling of the cementitious matrix. ${ }^{24.25}$ A more detailed compression model incorporating the fiber bending effect of Morton \& Grove was studied by Huang. ${ }^{2 h}$

Based on experimental evidence of single fiber pull-out test at pre-determined angles, Li et al. ${ }^{12}$ found that the fiber bridging force $P$ increases with inclination angle at a rate roughly described by the Euler friction pulley law:

$$
P(\delta ; \phi)=P(\delta ; \phi=0) e^{f \phi}
$$

where $f$ is a snubbing coefficient specific to a fiber/matrix combination and has to be determined experimentally. When this so-called snubbing effect is included in the fiber bridging analysis, $\mathrm{Li}^{13}$ found that eqn (7) is modified by a snubbing factor $g$ defined in terms of the snubbing coefficient:

$$
g \equiv \frac{2}{4+f^{2}}\left(1+e^{\pi f / 2}\right)
$$

Furthermore, if we linearize eqn $(7)$ in $\delta$, i.e. appropriately for $\delta<<L_{\mathrm{f}} / 2$, the fiber bridging stress becomes

$$
\tau_{\mathrm{B}}(\tilde{\delta})=\frac{1}{2} s V_{\mathrm{f}}(1-2 \tilde{\delta}) \quad \text { for } \tilde{\delta}>0
$$

where the reinforcement index $s$ is defined as

$$
s=g \tau_{\mathrm{f}}\left(\frac{L_{\mathrm{f}}}{d_{\mathrm{f}}}\right)
$$

For typical values of $f$ ranging from 0 to $1, g$ ranges from 1 to $2 \cdot 3$. Strictly speaking, the angle effect described in eqn (10) is correct only for the case of mode I type crack opening, since the ease of fiber page slip in mode II type crack sliding depends on the direction of sliding (Fig. 6). Because of the lack of experimental data from fiber pull-out tests in such sliding configurations, we assume for now that these differences from the mode I type behavior balance themselves out, and that eqn (10) may still be used.

The magnitude of sliding may vary over the length of the sliding crack, but should become more uniform with increasing length of the wingcracks. For simplicity, we assume a uniform distribution governed by the maximum sliding of a crack of length $a$ under shear load $\tau$. This leads to a sliding resistance due to fiber bridging which diminishes with the applied compressive load as the bridging fiber is pulled out:

$$
\tau_{\mathrm{B}}=\frac{1}{2} s V_{\mathrm{f}}\left[1-\frac{2 a \sigma}{L_{\mathrm{f}} G}(1-\mu)(1-v)\right]
$$

where $G$ and $v$ are the composite shear modulus and Poisson's ratio respectively. Note that eqn (12) probably underestimates the sliding magnitude since the presence of the wing-cracks would likely increase the compliance of the sliding microcrack. A better estimate may be to replace $a$ in eqn (12) by the wing-crack length. Another more sophisticated technique of estimating the microcrack sliding magnitude has been presented
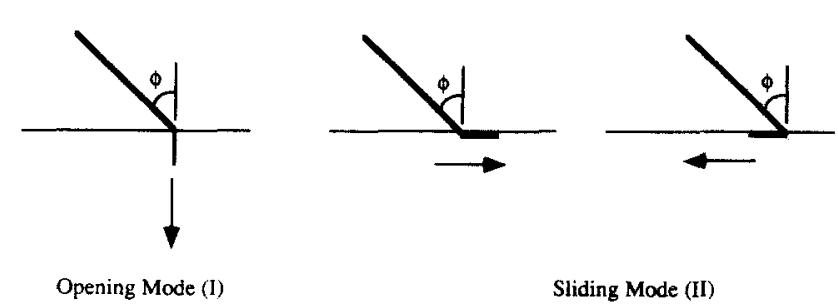

Fig. 6. Bridging action of a fiber crossing a mode I type and a mode II type microcrack. For the mode II type sliding microcrack, the one on the left is easier and the one on the right is more difficult to slide out. 
by Ashby \& Hallam, ${ }^{9}$ although the result is in a similar form as reflected in the second term in the square bracket of eqn (12).

The net shear stress acting on the sliding microcrack is therefore given by:

$$
\tau=\frac{1}{2} \sigma(1-\mu)-\tau_{\mathrm{B}}
$$

\section{Resistance to wing-crack growth}

The wing-crack, like the sliding microcrack, will also be bridged by fibers. In this case, however, the wing-crack opening and the bridging action will be in mode I. Further, as the wing-crack grows, increasing numbers of bridging fibers will lead to an increase in crack closing pressure in an enlarging 'process zone'. This type of behavior is well known and is often described in terms of an $R$ curve (resistance curve). The $R$ curve denotes a rising fracture energy and its shape is determined by the composite tension-softening behavior, ${ }^{27}$ and the geometry and loading configuration of the fracture specimen. ${ }^{28}$ A typical $R$ curve for FRC is shown schematically in Fig. 7. A bi-linearized version of the $R$ curve is also shown where the linear segments meet at $l=l^{*}$. From the numerical calculation of $\mathrm{Li}^{29}$ a suitable value of $l^{*}$ appears to be approximately $20 L_{\mathrm{f}}$. Because typical fiber lengths are around $5 \mathrm{~mm}$ or more, $l^{*}$ would be in the $100 \mathrm{~mm}$ range. This is definitely longer than the wing-crack length when the applied load reaches compressive strength. For this reason, only the first linear segment of the simplified $R$ curve need be used. These considerations then lead to a total toughness against which the wing cracks have to propagate:

$$
K_{\mathrm{IC}}=K_{\mathrm{m}}+\sqrt{l / l^{*} E G_{0}}
$$

where $E$ and $G_{0}$ are the composite Young's modulus and the composite fracture energy respectively. $G_{0}$ is the plateau value of the $R$ curve shown in Fig. 7. In the case of FRC, $\mathrm{Li}^{13}$ found that $G_{0}$ can be related to the fiber and interfacial properties:

$$
G_{0}=\frac{1}{12} s L_{\mathrm{f}} V_{\mathrm{f}}
$$

Combining eqns (4), (12), (13), (14) and (15) and enforcing the fracture criterion

$$
K_{1}=K_{\mathrm{IC}}
$$

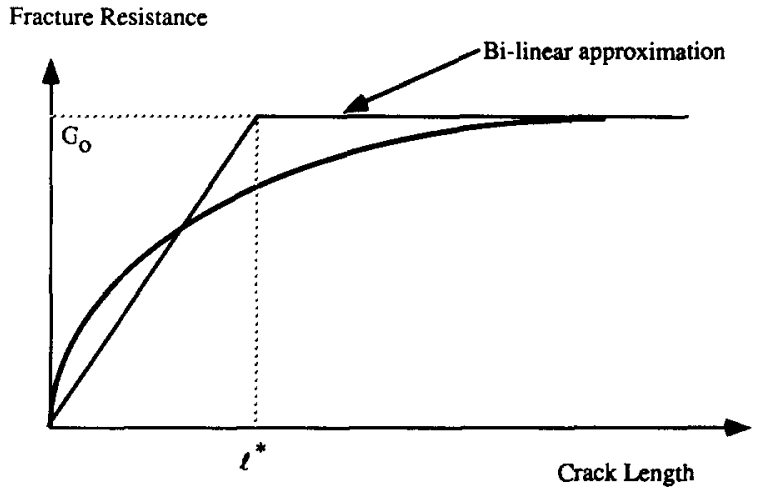

Fig. 7. A typical $R$ curve for FRC. Also shown is a bilinear approximation.

we obtain an expression relating the normalized compressive load $\sigma_{0}$ required to maintain the normalized wing-crack length $l_{0}$ :

$$
\sigma_{\mathrm{o}} \equiv \frac{\sigma \sqrt{\pi a}}{K_{\mathrm{m}}}=\frac{A\left[l_{0} ; a_{0} ; c ; V_{\mathrm{f}}\right]+C\left[K_{0} ; s_{0} ; V_{\mathrm{f}}\right]}{B\left[s_{0} ; V_{\mathrm{f}}\right]}
$$

where

$$
\begin{gathered}
A\left[l_{0} ; a_{0} ; c ; V_{\mathrm{f}}\right] \\
\equiv\left[1+\sqrt{\left(\frac{\bar{a}}{l_{0}^{*}}\right) c l_{0} V_{\mathrm{f}}} \sqrt{\left(\frac{2 \pi}{a_{0}}\right) \sin \left[\pi a_{0} l_{0}\right]}\right] \\
B\left[s_{0} ; V_{\mathrm{f}}\right] \equiv(1-\mu)\left[1+4\left(1-v^{2}\right) \bar{a} s_{0} V_{\mathrm{f}}\right] \\
C\left[K_{0} ; s_{0} ; V_{\mathrm{f}}\right] \equiv \frac{s_{0} V_{\mathrm{f}}}{K_{0}}
\end{gathered}
$$

and the non-dimensional parameters are defined as $l_{0} \equiv l / a ; \quad a_{0} \equiv a / b ; \quad l_{0}^{*} \equiv l^{*} / L_{\mathrm{f}} ; \quad \bar{a} \equiv a / L_{\mathrm{f}} ; \quad c \equiv$ $s L_{\mathrm{f}} E_{12} K_{\mathrm{m}}^{2} ; K_{0} \equiv K_{\mathrm{m}} / E \sqrt{\pi a} ; s_{0} \equiv s / E$.

\section{Assessment of fiber strengthening effect}

We are now in a position to assess the positive influence of fibers on the load-bearing capacity as the wing-cracks grow [Fig. 8(a)]. In this figure, the initial damage magnitude is fixed $(a / b=0 \cdot 1)$, and a family of curves is generated for various fiber volume fractions. (Other fixed parameters in this and subsequent calculations are $l_{0}^{*}=20 ; \bar{a}=0 \cdot 1$; $c=800 ; K_{0}=0.0002 ; s_{0}=0.01$. They are chosen to represent typical FRCs but can be adjusted for specific conditions.) Because $\sigma_{0}$ varies with $V_{\mathrm{f}}$ in the same manner as with $s$, this family of curves may also be interpreted as a result of the influence of the interfacial bond strength or fiber aspect ratio. Figure 8(b) shows the monotonic increase in compressive strength $\sigma_{\mathrm{c}}$ with fiber volume fraction. For the present set of parameters, compres- 

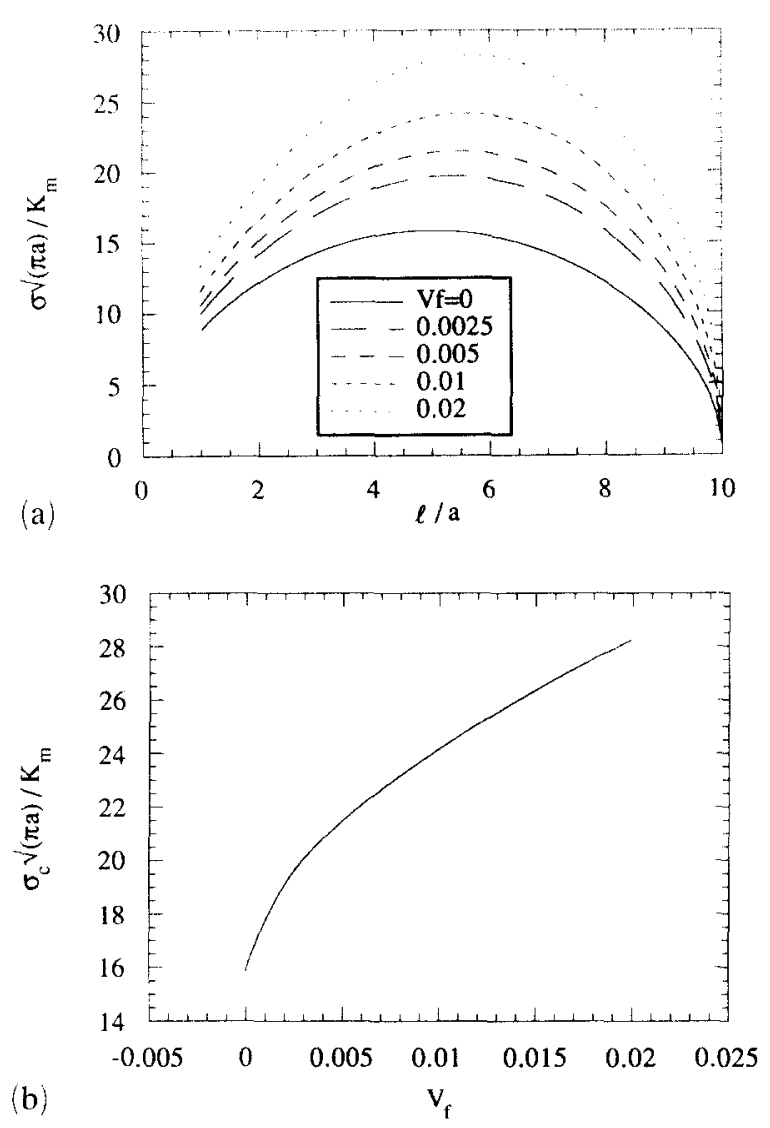

Fig. 8. Strengthening effect of fibers: (a) normalized compression load required to drive a wing-crack of length $l$, for five different fiber volume fractions; (b) predicted compressive strength increases with fiber volume fraction, when no fiber-induced damage effect is included. Parametric values used are $l_{0}^{*}=20 ; \quad a_{0}=0 \cdot 1 ; \quad \bar{a}=0 \cdot 1 ; \quad c=800$; $K_{11}=0.0002 ; s_{01}=0.01$.

sive strength is shown to increase by as much as $70 \%$ for $V_{\mathrm{f}}$ up to $2 \%$.

\section{WEAKENING EFFECT OF FIBER ADDITION}

As pointed out earlier, experimental observations suggest that fibers are not always beneficial to compressive strength, especially when the fiber volume increases beyond a certain level. We now turn our attention to study the influence of damage introduction due to the presence of fibers on the compressive strength of FRC. A convenient way of introducing this fiber-induced damage concept is by making the initial microcrack density parameter $a_{0}$ dependent on the fiber volume fraction. There are at present no experimental data which can be used to describe this dependence. However, FRC compressive strength reduction appears to correlate with void ratio, ${ }^{30}$ as indicated in Fig. 9. Conceptually, we can expect that the crack density may increase more than

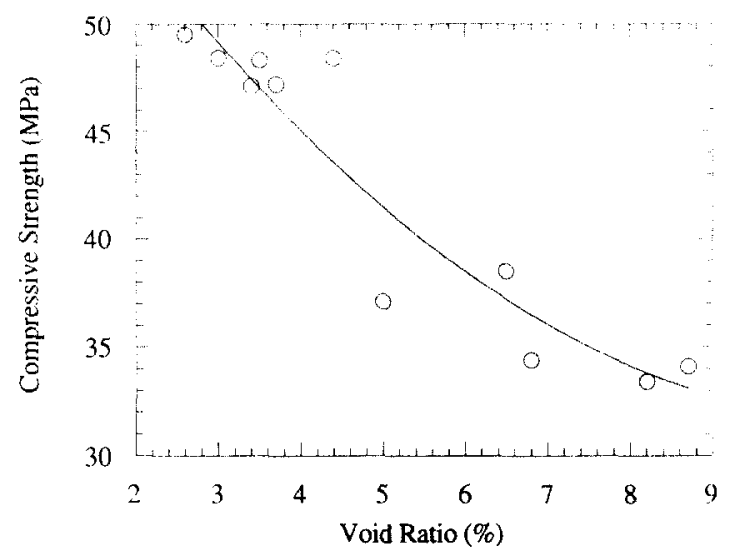

Fig. 9. Experimentally determined compressive strength reduction with void ratio (Ref. 30 ).

linearly with fiber addition, due to the rapid loss of workability. In the present work, we assume the simple function form

$$
a_{0}=\left(\frac{a}{b}\right) e^{k v_{\mathrm{f}}}
$$

to replace the previous definition of $a_{0}$ in eqn (17). In eqn (18), the fiber damage index $k$ represents the damage influence of fiber, and is probably sensitive to the type of fiber used as well as the cementitious material in the fresh state. This parameter could also be significantly influenced by processing conditions. Unfortunately none of this information is at present available.

We are now in a position to study the damage effect of fibers. For the sake of clarity, we 'turn off' the beneficial effect by setting the reinforcement index $s=0$ (so that $c=s_{0}=0$ ) in eqn (17). Figure 10 (a) shows a family of $\sigma_{0}-l_{0}$ plots for different $k$ values. As expected, as $k$ increases, crack-crack interaction becomes stronger and instability of the crack system occurs earlier at smaller wing-crack lengths. Simultaneously, the compressive strength drops. The decrease of compressive strength with fiber volume fraction at different $k$ values is shown in Fig. 10(b), which is not unlike the experimental data shown in Fig. 9. The compressive strength can be reduced by more than $50 \%$ depending on $k$ and $V_{\mathrm{r}}$.

\section{COMBINED STRENGTHENING AND WEAKENING EFFECT OF FIBER ADDITION}

Equations (17) and (18) may be used to study the effect of fiber on compressive strength in FRCs, when microcrack sliding resistance, wing-crack 
growth resistance and damage introduction are operational at once, as is suggested by experimental data such as those shown in Fig. 1. In Fig. 11 , we show that the compresive strength may continue to rise even beyond $4 \%$ when the fiber damage index is small (e.g. $k=10$ ), but rapidly drops beyond $0 \cdot 1 \%$ when the fiber damage index is large (e.g. $k=100$ ). Between these extremes, compressive strength is seen to rise initially with fiber volume fraction, and then to decrease with additional number of fibers. These predictions of fiber-induced compressive strength changes are in qualitative agreement with the experimental data shown in Fig. 1.

\section{FIBER/MATRIX INTERACTION AND FIBER GEOMETRY EFFECT}

It is interesting to note that while excessive amounts of fiber for a given fabrication process can lead to compressive strength degradation,
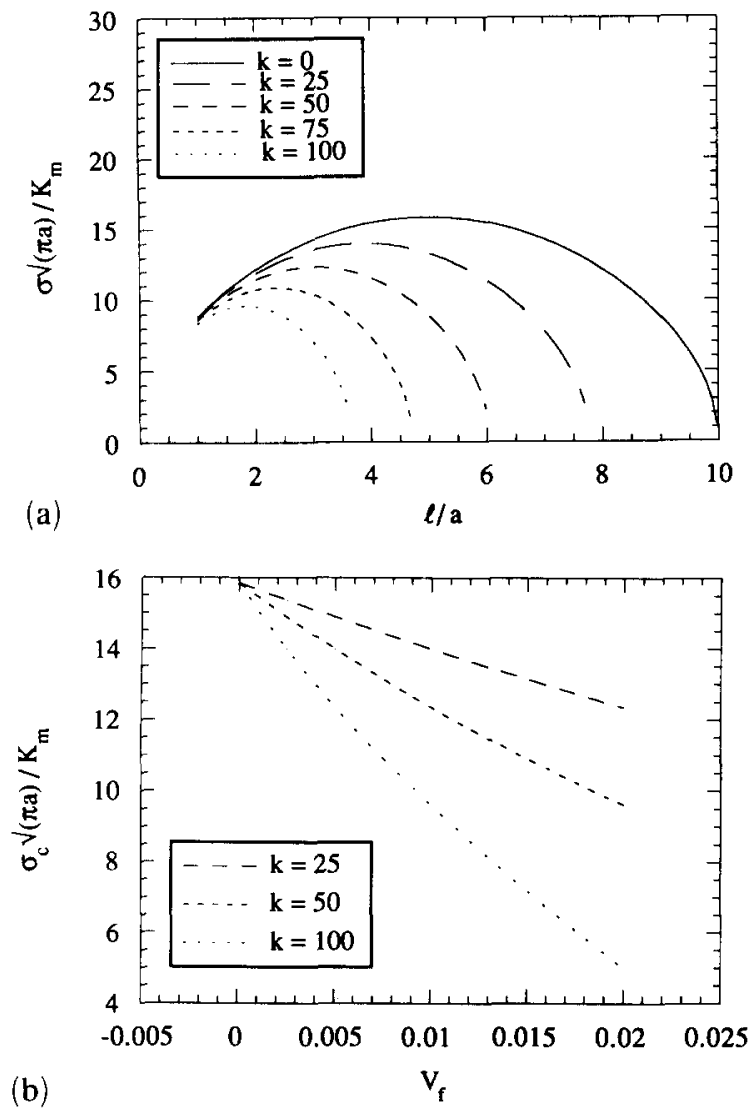

Fig. 10. Damage effect of fibers: (a) normalized compression load required to drive a wing-crack of length $l$, for five different fiber-induced damage indices $k\left(V_{\mathrm{f}}=0.01\right)$; (b) predicted compressive strength decreases with fiber volume fraction due to fiber-induced damage effect. Parametric values used are $l_{0}^{*}=20 ; a_{0}=0 \cdot 1 ; \bar{a}=0 \cdot 1 ; c=0 ; K_{0}=0 \cdot 0002$; $s_{0}=0$. alteration of fiber/matrix interaction properties, or the fiber geometry, can lead to beneficial effects without the attendant introduction of damage. For example, it is conceivable that fiber/matrix bond strength or the snubbing factor could be increased without causing a rise in the initial amount of damage. This is in fact one of the assumptions behind eqn (17), and we illustrate this idea with Fig. 12, which shows the relationship between compressive strength $\sigma_{\mathrm{c}}$ and the reinforcement index $s$, at a fixed fiber volume fraction and fiber damage index $\left(V_{\mathrm{f}}=0.01\right.$ and $\left.k=25\right)$. Note that the reinforcement index $s$, as defined in eqn (11), is directly proportional to $g, \tau_{\mathrm{f}}$ and $L_{\mathrm{f}} / d_{\mathrm{f}}$. Therefore variation in $s$ may be interpreted as variation in any one of these parameters, with the others fixed. Figure 12 indicates a monotonic increase in the compressive strength with the $s$-value, suggesting the importance of these parameters in controlling the compressive strength in FRCs. However, it should be pointed out that the amount of initial damage may be expected to
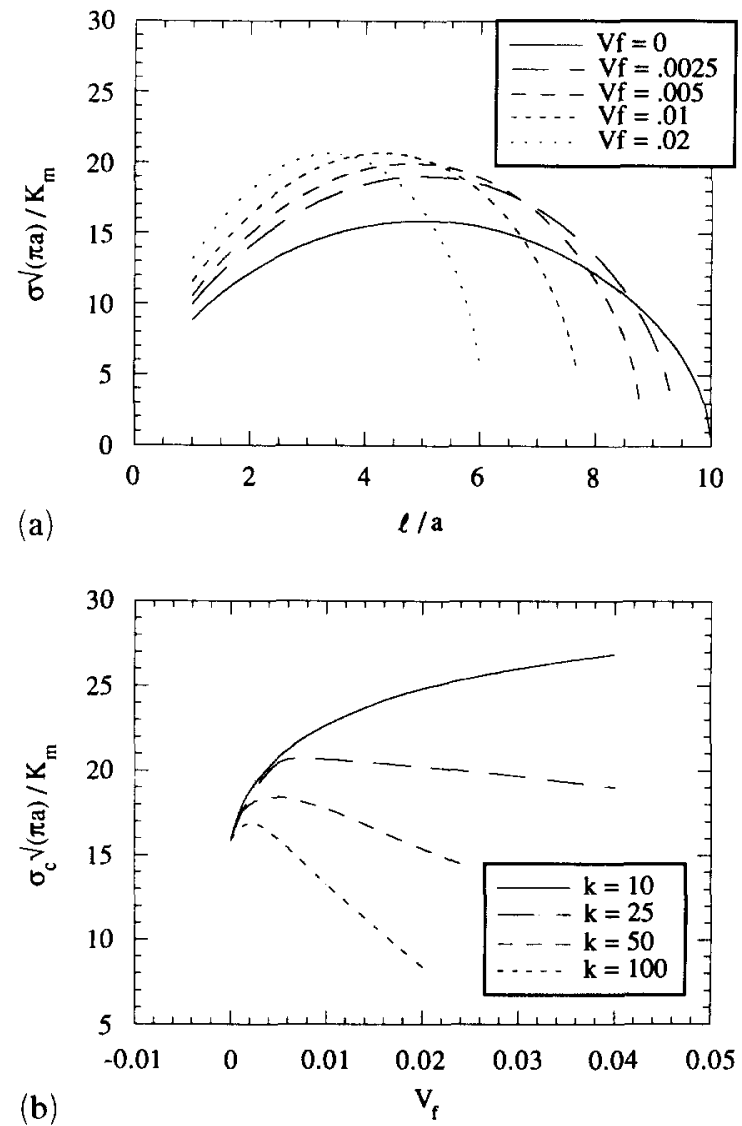

Fig. 11. Combined strengthening and damage effect of fibers: (a) parametric values used are the same as Fig. $8(\mathrm{a})$; (b) predicted compressive strength change with fiber volume fractions, for different fiber-induced damage indices $k$. Parametric values used are $l_{0}^{*}=20 ; a_{0}=0 \cdot 1 ; \bar{a}=0 \cdot 1 ; c=800$; $K_{0}=0.0002 ; s_{0}=0.01$. (a) (b) 


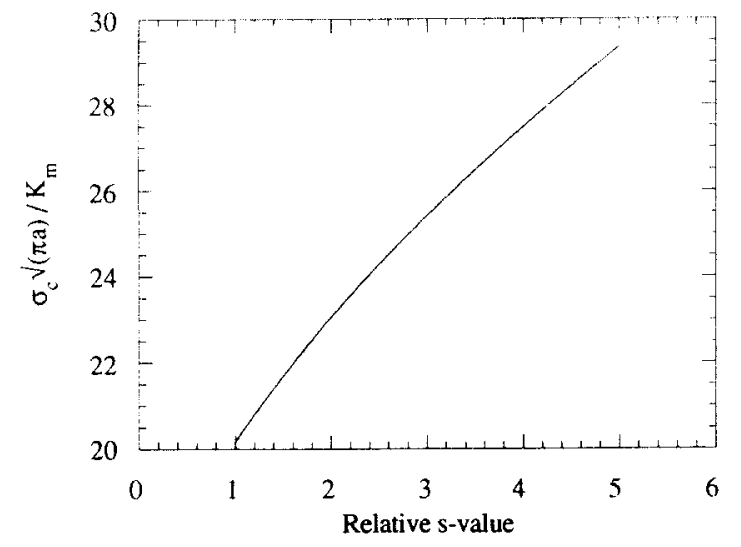

Fig. 12. Compressive strength increase with fiber reinforcement index $s$. The $s$ values have been normalized by the reference magnitude of $s$ such that $s_{0}=0.005$ and $c=800$ as used in all the preceding calculations. Other parametric values used are $I_{0}^{*}=20 ; a_{0}=0 \cdot 1 ; \bar{a}=0 \cdot 1 ; K_{0}=0 \cdot 0002 ; k=25$; $V_{1}=0.01$

increase with fiber aspect ratio, even though this notion has not been incorporated in the present model.

\section{FURTHER DISCUSSIONS AND CONCLUSIONS}

Although the microcrack sliding model of compressive strength in brittle material has been discussed [eqn. (6)] in the context of uniaxial loading in the present paper, extensive studies ${ }^{8-10}$ have shown that the compressive strength is very sensitive to confining stresses. That this is so can be seen in the sensitivity of the stress intensity factor of the wing-cracks to normal compressive load. This notion is in accord with experience in cementitious materials, for which confinements are general prescriptions to derive higher compressive load-bearing capacity. The present model of compressive strength for FRC shows that fibers can be exploited to increase the compressive strength and may therefore act as a passive confining pressure. This passive confinement idea was first proposed by Yin et al. ${ }^{14.15}$ who discovered this beneficial effect of fiber in a series of biaxial steel FRC tests.

The positive effect of fibers on the elastic modulus of composites has received extensive attention (e.g. Refs 31,32). However, it is also well known, at least for some cementitious composites, that fiber can degrade the composite modulus to below that of the matrix modulus (e.g. Ref. 33). It is likely that fibers would induce competing processes of modulus improvement and degradation in cementitious composites, in the same man- ner that they influence compressive strength. In fact, many of the basic elements of the present work could be applied to analyze FRC elastic modulus, and this is the focus of some ongoing work at the University of Michigan.

The present work represents a preliminary look at how fibers in FRC contribute or degrade composite mechanical properties. Many simplifying assumptions are made in an attempt to maintain mathematical tractability. In the process. however, only general qualitative trends are suggested. Quantitative predictions should be based on more accurate, albeit more complicated, models. Even so, the results based on the present model appear to capture much of what has been experimentally observed in compressive strength change due to fiber addition. The present work lays the basis for more sophisticated models, which can be extended to include the effect of multiaxial loading, and which can be used to analyze both compressive strength and elastic modulus of the composite. A better understanding of compressive strength and elastic modulus degradation requires the characterization of defects generated by fibers in a given matrix and fabrication process. Together with improved micromechanical models, it should enhance composite properties via microstructural control.

\section{ACKNOWLEDGEMENTS}

Research at the ACE-MRL has been supported by research grants from the National Science Foundation (program manager: Dr K. Chong) and from the Air Force Office of Sponsored Research (program manager: $\mathrm{Dr}$ Spencer $\mathrm{Wu}$ ) to the University of Michigan, Ann Arbor. Helpful discussions with $\mathrm{H}$. Horii, J. Huang, N. N. Jakobsen, J. Kemeny, D. Mishra and H. Stang are gratefully acknowledged.

\section{REFERENCES}

1. Li, V. C. \& Leung, C., Tensile failure modes of random discontinuous fiber reinforced brittle matrix composites. In Fracture Processes in Concrete, Rock and Ceramics, ed. J. G. M. van Mier, J. G. Rots \& A. Bakker, Chapman \& Hall, London, 1991, pp. 285-94.

2. Li, V. C. \& Wu, H. C., Pseudo strain-hardening design in cementitious composites. In High Performance Fiber Reinforced Cement Composites, ed. H. Reinhardt \& A. Naaman, Chapman \& Hall, London, 1992, pp. 371-87.

3. Li, V. C., Wang, Y. \& Backer, S., A micromechanical model of tension-softening and bridging toughening of 
short random fiber reinforced brittle matrix composites. J. Mechanics and Physics of Solids, 39 (5) (1991) 607-25.

4. Li, V. C., Wang, Y. \& Backer, S., Fracture energy optimization in synthetic fiber reinforced cementitious composites. In MRS Proceedings, Vol. 211, Fiber Reinforced Cementitious Materials, ed. S. Mindess \& J. Skalny, 1991, pp. 63-70.

5. Mobasher, B., Ouyang, C. \& Shah, S. P., Modelling of fiber toughening in cementitious materials using an $R$ curve approach. Int. J. Fracture, 50 (1991) 199-219.

6. Jakobsen, N. N., Microscopial investigation of reduced compressive strength of polypropylene fiber reinforced concrete. Paper presented at the Third Euroseminar on Microscopy applied to Building Materials, Barcelona, Spain, September 1991.

7. Jaeger, J. C. \& Cook, N. G. W., Fundamentals of Rock Mechanics, 3rd edition, Chapman and Hall, London.

8. Horii, H. \& Nemat-Nassar, S., Brittle failure in compression: splitting, faulting, and brittle-ductile transition. Phil. Trans. Royal Soc. London, 319 (1986) 337-74.

9. Ashby, M. F. \& Hallam, S. D., The failure of brittle solids containing small cracks under compressive stress states. Acta Metall, 34 (3) (1986) 497-510.

10. Kemeny, J. M. \& Cook, N. G. W., Micromechanics of deformation in rocks. In Toughening Mechanisms in Quasi-Brittle Materials, ed. S. P. Shah. Kluwer Academic, Amsterdam, 1991, pp. 155-88.

11. Li, V. C., The effect of snubbing friction on the first crack strength of flexible fiber reinforced composites. In Proc. 8th European Congress of Fracture: Fracture Behavior and Design of Materials and Structures, Vol II, ed. D. Firrao, Chameleon Press, London, 1990, pp. 738-45.

12. Li, V. C., Wang, Y. \& Backer, S., Effect of inclining angle, bundling, and surface treatment on synthetic fiber pullout from a cement matrix. J. Composites, 21 (2) (1990) 132-40.

13. Li, V. C., Post-crack scaling relations for fibre reinforced cementitious composites. ASCE J. Materials in Civil Engineering, 4 (1991) 41-57.

14. Yin, W. S., Su, C. M., Mansur, M. A. \& Hsu, T. T. C., Biaxial test of plain and fiber concrete. ACI Materials J., 86 (3) (1989) 236-43.

15. Yin, W. S., Su, C. M., Mansur, M. A. \& Hsu, T. T. C., Fiber reinforced concrete under biaxial compression. Engineering Fracture Mechanics, $35(1 / 2 / 3)$ (1990) 261-8.

16. Griffith, A. A., The phenomena of rupture and flow in solids. Phil. Trans. Series A, 221 (1920) 163-98.

17. Sammis, C. G. \& Ashby, M. F., The failure of brittle porous solids under compressive stress states. Acta. Metall., 34 (1986) 511-26.

18. Huang, Q. J. \& V. C. Li., A meso-mechanical model of the tensile behavior of concrete - Part I: Modelling of pre-peak stress-strain relation. J. Composites, 20 (4) (1989) 361-9.

19. Horii, H., Hasegawa, A. \& Nishino, F., Fracture process and bridging zone model and influencing factors in fracture of concrete. Fracture of Concrete and Rock, ed. S. P. Shah \& S. E. Swartz. Springer-Verlag, New York, 1989, pp. 205-19.

20. Bazant, Z. P., Snapback instability at crack ligament tearing and its implication for fracture micromechanics. Report No. 87-6/498s, Center for Concrete and Geomaterials, Northwestern University, June 1987.

21. Ortiz, M., Microcrack coalescence and macroscopic crack growth initiation in brittle solids. Int. J. Solids and Struct., 24 (3) (1988) 231-50.
22. Rooke, D. P. \& Cartwright, D. J., Compendium of Stress Intensity Factors. The Hillingdon Press, Middx, UK, 1976.

23. Morton, J. \& Groves, G. W., The effect of metal wires on the fracture of a brittle matrix composite. J. Materials Science, 11 (1976) 617-22.

24. Leung, C. K. Y. \& Li, V. C., Effect of fiber inclination on crack bridging stress in brittle fiber reinforced brittle matrix composites. Accepted for publication in J. Mech. \&Phys. Solids, 1992.

25. Wang, Y., Li, V. C. \& Backer, S., Tensile failure mechanisms in synthetic fiber reinforced mortar. $J$. Materials Science, 26 (1991) 6565-75.

26. Huang, Q. J., Micromechanical modelling of the fracture behavior of second-phase reinforced cementitious materials. PhD thesis, MIT, 1990.

27. Wang, Y., Li, V. C. \& Backer, S., Tensile properties of synthetic fiber reinforced mortar. J. Cement and Concrete Composites, 12 (1) (1990) 29-40.

28. Li, V. C., Wang, Y. \& Backer, S., Effect of fiber-matrix bond strength on the crack resistance of synthetic fiber reinforced cementitious composites. In MRS Symposia 114. Bonding in Cementitious Composites, ed. S. Mindess \& S. Shah, Materials Research Society, Pittsburgh, Pennsylvania, 1988, pp. 167-74.

29. Li, V. C., Non-linear fracture mechanics of inhomogeneous quasi-brittle materials. In Non-Linear Fracture Mechanics. ed. M. P. Wriek, Springer-Verlag Wien, New York, pp. 143-92, 1990.

30. Ward, R., Yamanobe, K., Li, V. C. \& Backer, S., Fracture resistance of acrylic fiber reinforced mortar in shear and flexure. In Fracture Mechanics: Application to Concrete, ed. V. Li \& Z. Bazant. ACI SP-1 18, 1989, pp. 17-68.

31. Tandon, G. P. \& Weng, G. J., Average stress in the matrix and effective moduli of randomly orientated composites. Composites Science and Technology, 27 (1986) 1 1 1-32.

32. Wakashima, K. \& Tsukamoto, H., Mean-field micromechanics model and its application to the analysis of thermomechanical behavior of composite materials. Materials Science and Engineering $A(1991)$ in press.

33. Naaman, A., Otter, D. \& Najim, H., Elastic modulus of SIFCON in tension and compression. ACI Materials Journal, 88 (6) (1991).

34. Akihama, S., Nakagawa, H., Takada, T. \& Yamaguchi, M., Experimental study on aramid fiber reinforced cement composites 'AFRC' mechanical properties of AFRC with short fibers. In RILEM Symposium on Developments in Fiber Reinforced Cement and Concrete, FRC86, Vol. 1, ed. R. N. Swamy, R. L. Wagstaffe \& D. R. Oakley, 1986, Paper 2.5.

35. Ward, R. \& Li, V.C., Dependence of flexural behavior of fiber reinforced mortar on material fracture resistance and beam size. J. Materials, American Concrete Institute, $87(6)(1990) 627-37$

36. Zhu, B. Y., Behavior of concrete with synthetic organic fibers. Darmstadt Concrete, 5 (1990) 249-55.

37. Akihama, S. \& Suenaga, T., Influences of fiber strength and polymer impregnation on the mechanical properties of carbon fiber reinforced cement composites. In RILEM Symposium on Developments in Fiber Reinforced Cement and Concrete, FRC86, Vol. 1, R. N. Swamy, R. L. Wagstaffe \& D. R. Oakley. 1986, Paper. 2.3 .

38. Tjiptbroto, P., Tensile strain hardening of high performance fiber reinforced cement based composites. PhD thesis, Department of Civil Engineering, University of Michigan, 1991. 